\title{
Evaluating the Safety of Medication Exposures During Pregnancy: A Case Study of Study Designs and Data Sources in Multiple Sclerosis
}

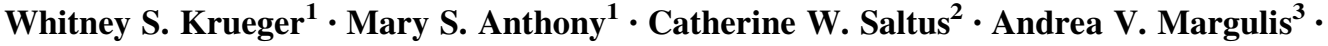 \\ Elena Rivero-Ferrer ${ }^{3} \cdot$ Brigitta Monz $^{4} \cdot$ Ceri Hirst $^{4} \cdot$ David Wormser $^{4}$. \\ Elizabeth Andrews ${ }^{1}$
}

Published online: 29 July 2017

(C) The Author(s) 2017. This article is an open access publication

\begin{abstract}
Background Regulatory agencies often request prospective, product-specific post-authorization pregnancy exposure registries to monitor safety during pregnancy, even though studies using existing health databases could also be employed.

Objectives Using multiple sclerosis (MS) as a case study, we evaluated various study designs and data sources previously used to study medication exposure in pregnancy. Methods We examined (1) strengths and limitations of study designs used for pregnancy safety studies in women exposed to MS-specific medications during pregnancy and (2) existing data sources used to conduct such studies in other disease areas. For the data sources identified, we contacted data custodians to determine the feasibility of assessing the risk of adverse outcomes in women with MS exposed to disease-modifying therapies (DMTs) during pregnancy.

Results Of 43 MS-specific studies identified, most of which were prospective registries, very few, regardless of design and
\end{abstract}

Electronic supplementary material The online version of this article (doi:10.1007/s40801-017-0114-9) contains supplementary material, which is available to authorized users.

Whitney S. Krueger

wkrueger@rti.org

1 RTI Health Solutions, 200 Park Offices Drive, Research Triangle Park, NC 27709, USA

2 RTI Health Solutions, 307 Waverley Oaks Road, Suite 101, Waltham, MA 02452-8413, USA

3 RTI Health Solutions, Av. Diagonal 605, 9-1, 08028 Barcelona, Spain

4 F. Hoffmann-La Roche Ltd. Real World Data Science, Grenzacherstrasse 124, 4070 Basel, Switzerland study population, produced timely and robust results for spontaneous abortions and major congenital malformations, considering study duration, achievement of target enrollment numbers, inclusion of internal comparators, and publication of results. Building on the successful use of existing healthcare databases to investigate drug safety during pregnancy in other disease areas, we identified 13 data sources that could be used to study intravenous DMT exposures in women with MS.

Conclusions Prospective, treatment-specific registries have generally failed to deliver robust information. For this reason, other study approaches, in particular cohort studies using existing healthcare databases, should be considered for evaluating the safety of drug exposure in pregnancy, including in MS.

\section{Key Points}

To evaluate the safety of medications during pregnancy for women with MS, prospective registries and other targeted studies have mostly failed to deliver timely and robust information. Other disease areas have effectively used existing healthcare databases for these types of studies.

While these limitations have been acknowledged by regulatory agencies, medication-specific prospective pregnancy registries are often requested to assess the safety of new medications, even though other study designs may be suitable.

Researchers should consider using existing healthcare databases and national registries to evaluate the safety of new medications among women with MS with exposure to disease-modifying therapies during pregnancy. 


\section{Introduction}

Ensuring the safety of pregnant women and their infants when exposed to medications is of primary importance to pharmaceutical companies, regulators, physicians, and patients. Pregnant women are excluded from most clinical trials, and the application of teratogenic findings from animal studies to humans can be unreliable. If the medication target population includes women of child-bearing potential or when safety concerns for use during pregnancy emerge before or after the drug is on the market, regulatory agencies require that pharmaceutical companies investigate medicine safety during pregnancy in the post-authorization phase [1]. In the USA, most of these regulatory requests have been for prospective cohort studies, often in the form of product-specific pregnancy exposure registries [2]. Certain characteristics and capabilities are needed for any study design or data source intended to evaluate medication exposure in pregnancy and fetal/infant outcomes: accurate measurement of medication exposure; identification of the timing of exposure during pregnancy, since medication effects on congenital malformations depend on specific timing during fetal development; identification of pregnancies early, if evaluating spontaneous abortions; identification of all offspring and follow-up for 1 year of life (to identify birth defects that may not be obvious at birth); accurate ascertainment of outcomes; use of appropriate comparison or referent population; and inclusion of a sufficient number of pregnancies to generate outcome measures with appropriate statistical precision. Prior studies have reported target populations of 150-300 medicationexposed pregnancies. Such targets, often considered operationally feasible, facilitate identification of increases in the prevalence of overall birth defects and more common outcomes, but are not sufficient to rule out increased risks of specific birth defects. Although prospective studies are designed to include these study characteristics, actual study experience may reveal limitations. Likewise, the use of existing health records must be evaluated carefully to assure that the required characteristics are present, accurate, and complete.

Multiple sclerosis (MS) is an autoimmune disease that often affects women of child-bearing age and for which several new medications have become available within the last two decades. It is therefore an ideal example to review the types of study designs and data sources used to address safety concerns in pregnancy and their ability to provide timely and robust evidence. The study of treatment safety during pregnancy among women with MS poses challenges that may be equally applicable to other diseases. Women are generally advised to stop treatment before attempting conception or as soon as the pregnancy is recognized, which reduces the exposed population to women with unintended exposure or to women in whom the benefit of treatment may outweigh any potential risks to the fetus.

Using MS as an example, our first objective was to identify post-authorization pregnancy safety studies and to describe the strengths and limitations of the study designs as related to the ability of each approach to adequately quantify risks to mother, fetus, and infant. Our second objective was to identify and evaluate the strengths and limitations of existing data sources (including populationbased registries or existing healthcare databases) that could be used to evaluate the same research questions. Because such data sources have not commonly been used in MS, we further assessed the feasibility of conducting a database study to evaluate the risk of adverse outcomes in women with MS exposed to MS-specific medications during pregnancy.

\section{Methods}

Using MS as a case study, for the first objective, we reviewed published literature, conference abstracts, and clinical trial registry websites to identify pregnancy safety studies. Studies were non-interventional, investigated pregnant women with MS and MS treatment exposures, and had at least one of the following outcomes: pregnancy outcomes, fetal or infant outcomes, or obstetric or birth complications. Studies were evaluated on their ability to deliver timely and robust information, based on the following criteria: timeliness of results (5- to 10-year study duration with publication of results in a peer-reviewed journal), achievement of target enrollment numbers, and inclusion of internal comparators. Details about each study were extracted into summary tables.

For the second objective, we reviewed the published literature to identify studies published since 2000 that examined the association of maternal drug exposure with the risk of congenital malformations in any disease (to ensure that mother-infant linkage was possible), using population-based registries or existing healthcare databases that prospectively record data. Summary tables characterizing each data source were populated with information from peer-reviewed articles and supplemented with information found online.

We then explored the feasibility of conducting a pregnancy safety study, where the medication of interest would be a biologic administered by specialists, among women with MS using population-based registries or healthcare databases. For data sources identified, we obtained information from data custodians to confirm that the population, medication exposures, and outcomes for this study could be identified. In addition to the previously identified study characteristics and capabilities needed, we also explored 
whether it was possible to conduct validation against health records, lag time until data become available, and approximate number of women of child-bearing age with MS.

\section{Results}

\subsection{Objective 1: Post-Authorization Pregnancy Safety Studies in Women with Multiple Sclerosis (MS)}

A total of ten industry-sponsored MS drug-specific pregnancy exposure registries were identified: three completed registries, two terminated registries, four ongoing registries, and one planned registry that started enrolling patients after this literature review was conducted (Table 1) [3-20].

Two of the three completed registries exceeded their planned enrollment targets and collected information on more than 300 exposed pregnancies during study periods lasting 6 and 8 years, respectively [11, 18]. However, ongoing or final results for these two studies were published only as abstracts in conference proceedings [12-14, 19]; final study results were never published in the peer-reviewed literature. The third completed registry met about $25 \%$ of its planned target over a period of 7 years (2 years longer than originally planned), collecting information on 113 exposed pregnancies [16]. This was the only registry to publish results in a peer-reviewed journal, 2 years after the study ended [17]. The authors reported that while definitive conclusions could not be made due to the small study size, results did not indicate an increased risk of spontaneous abortions or birth defects, and the authors recommended continued monitoring through routine post-authorization surveillance activities.

Two registries were terminated due to low enrollment $[7,15]$. One registry had a target of 300 women and noted that despite "a consistent and exhaustive expenditure of resources over 5 years, only 36 patients were enrolled into the registry" [15]. This was the only registry out of all ten registries to include an internal comparison group of unexposed pregnant women with MS.

For all ten registries, the mean planned enrollment period was 7.6 years (range 5-11 years). The planned or actual period of infant follow-up after birth varied from 8 to 12 weeks to 1 year after birth, with five of ten registries following infants for 1 year.

In addition to the ten drug-specific registries, we identified three disease-specific MS pregnancy registries that were established to evaluate risks associated with MS and its therapies. Fifteen publications associated with these registries were identified (Table $\mathrm{S} 1$ online): 11 included an internal medication-unexposed group and a disease-matched comparator group, and two also included a comparison group of healthy women without MS [21, 22]. Excluding two case series using data from an MS-specific registry, the mean study size of the exposed populations was 91 women or pregnancies. Eleven publications reported the duration of the study period, with an overall mean of 7.2 years. Ten analyses reported prospective follow-up of participants postpartum.

We also identified seven prospective cohort studies (five treatment-specific and two disease-specific studies), four retrospective chart review studies, six purpose-built database studies, and one population-based database study (Table S1 online). Similar to the registry studies, these studies were generally uninformative due to small numbers of exposed pregnancies and of comparators (which were included by two-thirds of the studies). The one study based on existing health databases covered the population of British Columbia in Canada [23]. This database study spanned 12 years and included two comparator groups (unexposed births and previously exposed births among disease-matched women). While this study was robustly designed, it included a low number of DMT exposures $(n=21)$.

\subsection{Objective 2: Pregnancy Safety Studies Using Existing Databases}

From a comprehensive list of potential healthcare data sources in the USA, Canada, Europe, and Australia, peerreviewed publications involving 21 data sources were identified: ten healthcare claims databases, seven medical records databases, and four population-based national registries (Table 2). The studies reported in the publications evaluated the effects of drug exposure during pregnancy and risk of congenital malformations. All included information on medication dispensing or prescribing, with the associated date, which can be used to estimate the gestational timing of the exposure. Some sources did not identify all pregnancies at an early stage, and therefore could not capture all early pregnancy losses. However, all were able to capture deliveries and link mothers' records to their infants' records. All data sources included information about congenital malformations, usually as diagnostic codes in billing records. Access to health records for validation (a key feature for some of the infant outcomes) was possible for the majority of these data sources (81\%).

Because data are collected for routine purposes rather than for research, healthcare databases include all relevant patients. As long as individuals maintain care through their provider (in the case of seven data sources) or insurance company (ten data sources), their records are available and allow infant follow-up for 1 year after birth. For the four 


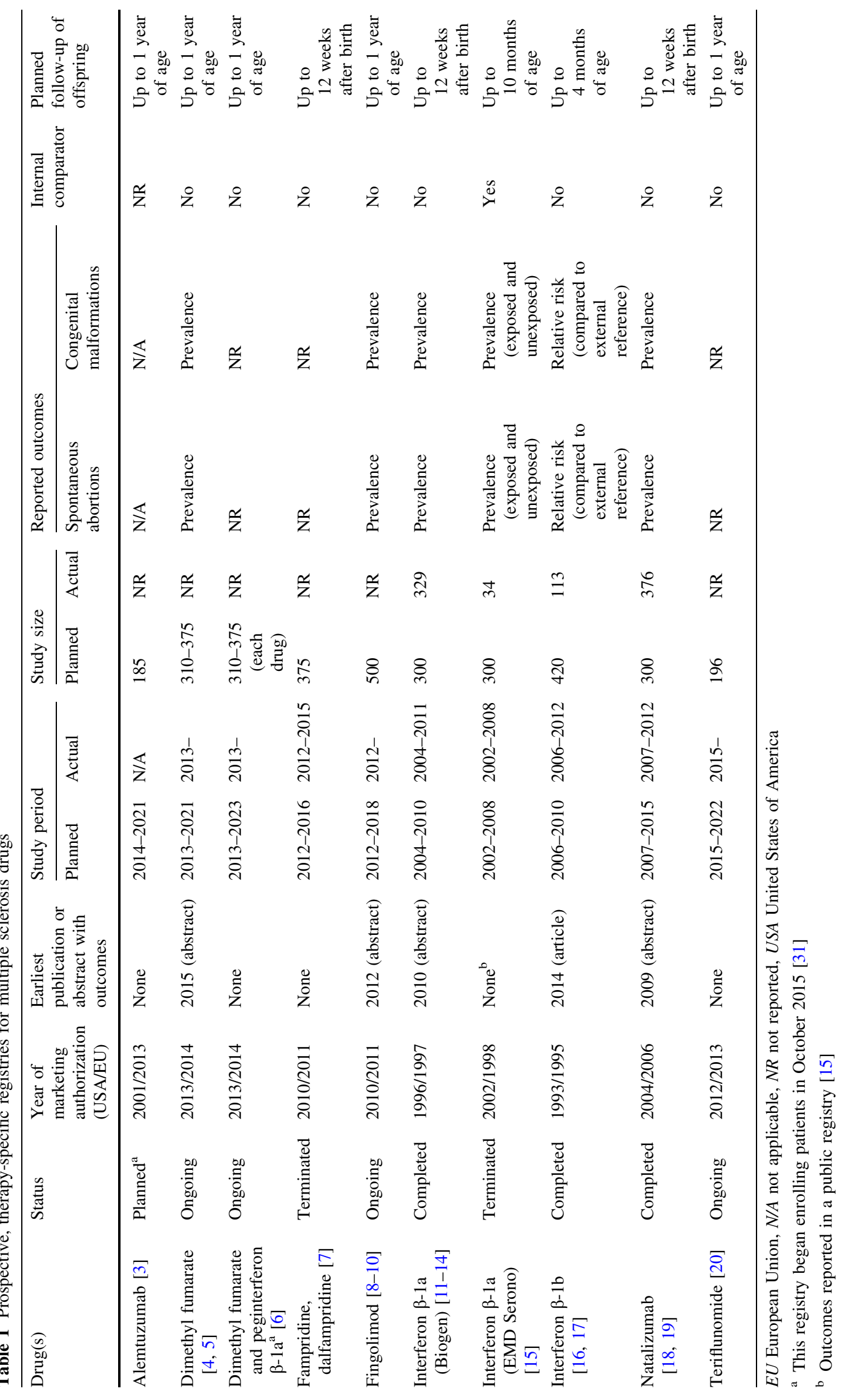




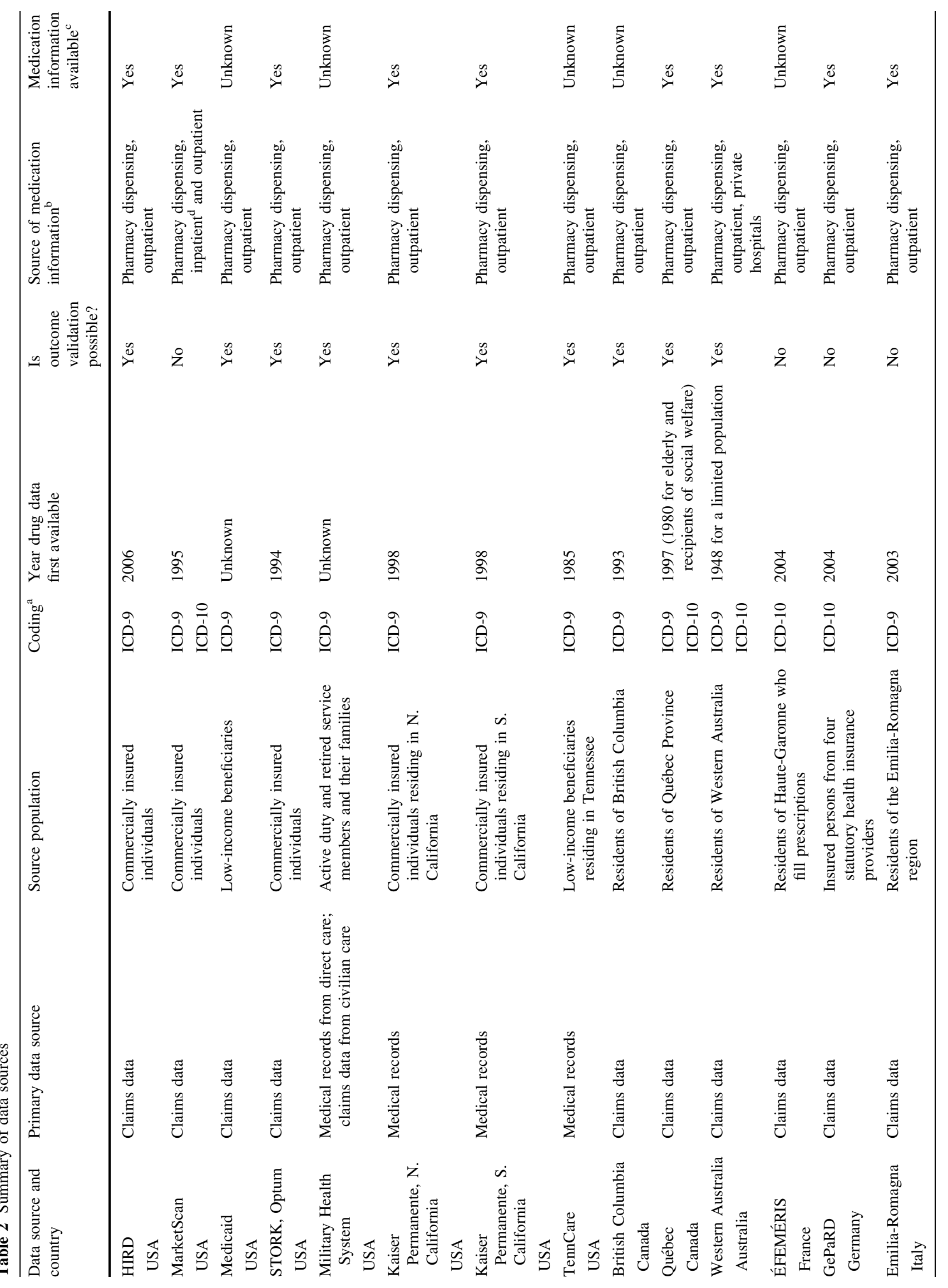




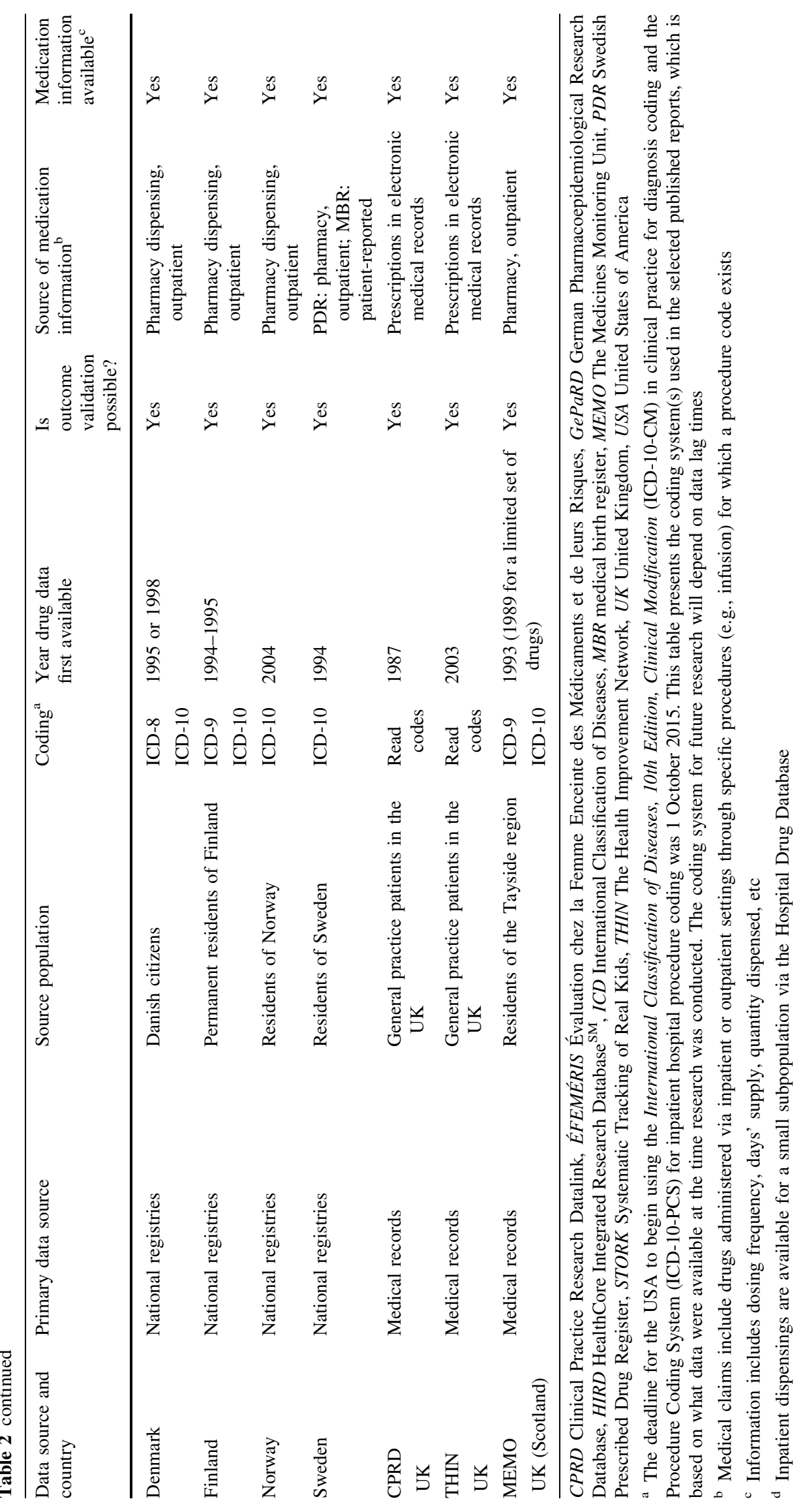


Table 3 Information on potential data sources suitable to study pregnancy and infant outcomes among women exposed to multiple sclerosis treatments

\begin{tabular}{|c|c|c|c|}
\hline Data source and country & $\begin{array}{l}\text { Data lag/ time } \\
\text { to data completion }\end{array}$ & Patients' duration in database ${ }^{a}$ & $\begin{array}{l}\text { Number of women aged } \\
15-45 \text { years with MS (time } \\
\text { frame) })^{\mathrm{b}}\end{array}$ \\
\hline $\begin{array}{l}\text { HIRD } \\
\text { USA }\end{array}$ & 6 months & $\sim 3$ years & 31,295 (Jan 2006-Apr 2016) \\
\hline $\begin{array}{l}\text { MarketScan } \\
\text { USA }\end{array}$ & $\begin{array}{l}\sim 6 \text { months; depends on } \\
\text { data type }\end{array}$ & $\begin{array}{l}\text { Mean: } 2.6 \text { years for mothers, } 2.7 \text { years for } \\
\text { fathers, } 2.5 \text { years for offspring }\end{array}$ & $25,729(2014)$ \\
\hline $\begin{array}{l}\text { Medicaid } \\
\text { USA }\end{array}$ & 18 months & Unknown & Estimated: $\sim 23,819(2011)^{\mathrm{c}}$ \\
\hline $\begin{array}{l}\text { STORK, Optum } \\
\text { USA }\end{array}$ & 6-9 months & $\sim 2.5$ years & $7421(2015)$ \\
\hline $\begin{array}{l}\text { KPNC } \\
\text { USA }\end{array}$ & A few weeks & Unknown & $1200(2015)$ \\
\hline $\begin{array}{c}\text { KPSC } \\
\text { USA }\end{array}$ & 1 year & $\begin{array}{l}\text { Mean: } 9.5 \text { years for mothers, } 11 \text { years for } \\
\text { fathers, } 5 \text { years for } 70 \% \text { of offspring }\end{array}$ & $1395(2015)^{\mathrm{d}}$ \\
\hline $\begin{array}{l}\text { TennCare } \\
\text { USA }\end{array}$ & 6 months to 1 year & $\begin{array}{l}43 \text { months for mothers, } 63 \text { months for offspring } \\
\text { (fathers not assessed) }\end{array}$ & $976(2013)$ \\
\hline $\begin{array}{l}\text { Québec } \\
\text { Canada }\end{array}$ & 12 months & $\begin{array}{l}\text { Maximum: } 17 \text { years for mothers and offspring; } \\
\text { no follow-up of fathers }\end{array}$ & $491(2015)$ \\
\hline $\begin{array}{l}\text { GePaRD } \\
\text { Germany }\end{array}$ & $\sim 2$ years & Unknown & Unknown \\
\hline Denmark & Variable, depends on data & During a patient's residence in Denmark & Unknown \\
\hline Norway & 4-5 months & During a patient's residence in Norway & $\sim 2000$ \\
\hline Sweden & Not applicable ${ }^{\mathrm{e}}$ & During a patient's residence in Sweden & Unknown \\
\hline $\begin{array}{l}\text { MEMO } \\
\text { Scotland }\end{array}$ & 6 months to 1 year & Until a patient's death or censorship & $\begin{array}{l}\text { Scotland: 2580; Tayside: } \sim 300 \\
\quad \text { (to June 2015) }\end{array}$ \\
\hline
\end{tabular}

GePaRD German Pharmacoepidemiological Research Database, HIRD HealthCore Integrated Research Database ${ }^{\mathrm{SM}}, K P N C$ Kaiser Permanente Northern California, KPSC Kaiser Permanente Southern California, MEMO Medicines Monitoring Unit, MS multiple sclerosis, STORK Systematic Tracking of Real Kids

${ }^{\text {a }}$ Questionnaire asked what is the average amount of time (in months or years) that adult mothers, adult fathers, and offspring remain in the database

b This number does not reflect how many women of childbearing age would be exposed to a specific MS treatment

c Some data sources require collaboration with an academic institution that would analyze the data

${ }^{\mathrm{d}}$ In-house analysis means that analyses must be conducted only by the data custodian or selected academic partners

e Most Swedish registries release data only once a year

national registries, 1-year follow-up is available for all infants.

From the 21 identified data sources, 13 were selected as feasible options for conducting pregnancy safety studies among women with MS, because of their large size and the potential to study intravenous DMT exposures during pregnancy and the risk of congenital malformations (Table 3): six use medical insurance claims as their primary source of data, four use medical records, and three use information collected via national registries. Eleven of these data sources are able to validate outcomes; most use medical record review only, while two data sources use medical record review and information collected in registries.

\section{Discussion}

For both new and existing medications, many post-marketing studies are conducted on safety during pregnancy. Therefore, we undertook this review to objectively evaluate the strengths and limitations of various approaches that have been used. Because MS is a disease that affects women of reproductive age, we focused on safety studies of DMTs among pregnant women with MS. The objective of the first literature review was to identify the strengths and limitations of various approaches to study the safety of MS medication exposure during pregnancy. Of the 43 publications identified, most arose from studies with a prospective design: MS medication-specific prospective 
pregnancy registries $(n=10)$, prospective cohort studies $(n=7)$, or MS-specific disease registries (15 publications from three registries). Four publications were from retrospective chart reviews, one from a study linking population-based medical registries in British Columbia, and six were from studies that used purpose-built databases for the study of the medications involved.

Our review revealed that only two MS medicationspecific registries were able to produce results for the most frequently investigated outcomes, spontaneous abortions and major congenital malformations, in study periods lasting 6 and 8 years using study sizes of 376 and 329 women, respectively. However, an internal comparator was unavailable for both registries, and results were never published in the peer-reviewed literature, which limited interpretation of and accessibility to the results. Of note, the natalizumab registry, which exceeded its enrollment target early, was conducted in the unusual context of a restricted drug distribution system in which the sponsor had ongoing contact with every patient receiving the medication. The other eight treatment-specific registries initiated soon after product launch failed to provide clinically meaningful information in a timely manner (Table 1).

Advantages of using data from prospective registries include having access to detailed patient-level data via systematically collected information on exposures, outcomes, and potential confounders, ensuring good data quality with up-to-date information. In addition, data collection can be tailored to specific research needs or focused on a study population with specified criteria, such as disease severity. Prospective studies can also gather information on previous treatments or obstetric information, which may not be available from healthcare databases. In settings where health services are not provided or paid by a single entity (e.g., obstetric care covered by health insurance and elective termination paid out of pocket), prospective studies may be able to capture patient medical history more completely than retrospectively analyzed data such as claims data.

In our evaluation of prospective pregnancy registries among women with MS, many were hampered by small numbers of patients, mainly due to difficulties in recruitment, leading to limited statistical precision. Also, recruitment started too late to capture early pregnancy losses. Furthermore, lack of reporting of some data elements in publications, such as the number of enrollees (e.g., see Table 1), represents an additional limitation, albeit one easy to overcome, to the value of these studies to clinicians, patients, researchers, and the scientific community in general. Most registries lacked suitable internal comparator populations, which is important for deriving relative risks with high internal validity. The registries were also limited by short follow-up periods for monitoring offspring, with only half the registries following infants to 1 year of age. One year is generally recommended to detect or exclude more subtle developmental or immunological effects and some malformations (such as some heart defects). In addition, the registry outcomes were rarely published in medical literature or were published many years after product launch. The other prospective cohort studies had similar limitations (Table S1).

These challenges, along with the awareness that even a pregnancy registry that meets its enrollment goal is usually underpowered to robustly evaluate safety events, suggest that prospective pregnancy registries alone are not the optimal approach to obtain adequate information on the risk of specific congenital malformations [2]. It is commonly acknowledged that the prevalence of overall birth defects is crude and less informative than the prevalence of specific defects, but most prospective registries are only able to evaluate the prevalence of overall birth defects, characterize the reported defects qualitatively, and identify an unusual pattern of birth defects. While these limitations have been acknowledged by the US Food and Drug Administration (FDA) and European Medicines Agency $[24,25]$, medication-specific prospective pregnancy registries are still the approach most commonly requested by the FDA to assess the safety of new medications, including for the most recently approved MS medication [26].

Similar to medication-specific registries, the diseasespecific registries identified in the literature review (Table S1) were limited by small numbers, short follow-up time, and enrollment too late to evaluate early pregnancy losses. The retrospective studies identified in the literature review were limited by the size of the data sources used. Only one of the database studies used linked populationbased data; however, that population (British Columbia) was small, with only 21 DMT-exposed pregnancies ascertained. Nonetheless, the design features of this study, including data linkages between mother and offspring, maternal prescription data, and sufficient follow-up of offspring for adverse outcomes, demonstrated that population-based database studies should be a feasible study approach, if enough women are exposed to the treatment of interest. To achieve this, larger databases or combined results from several databases are needed to obtain an adequate number of women with MS who are exposed to medications during pregnancy and to accommodate one or more internal comparator groups.

To see whether such an approach was successfully applied in other disease areas and to identify the databases used, we conducted a second literature review. Twenty-one data sources in the USA, Canada, Europe, and Australia were identified that were known to provide medication data for mothers and permit record linkage to their offspring to support studies on the effects of drug exposure during 
pregnancy and risk of congenital malformations. Analyses of data from population-based registries and healthcare databases have proven valuable when evaluating questions about drug safety during pregnancy in diverse disease areas and for different drugs [27-29], and database studies are therefore now more widely used.

From this pool of databases, 13 data sources were selected to further investigate DMT drug exposure during pregnancy in women with MS. All could identify the relevant exposures, estimate the gestational timing of exposure, identify pregnancy outcomes and follow infants for 1 year after birth. Information on comparators was readily available. Most but not all could conduct outcome validation. Because exposure to DMT in pregnancy is relatively uncommon, multiple data sources would likely be needed to achieve a meaningful study size within a reasonable time.

A cohort study design set within one or more existing databases for retrospective analyses has some notable scientific advantages. Secondary data lend themselves to the study of multiple endpoints and can be expanded to include additional outcomes if necessary. Because data are captured for routine purposes, such as medical claims and mandatory population-based reporting (e.g., Nordic countries), studies are free of research-related biases such as selective enrollment and follow-up, and multiple internal comparator groups can be utilized. When data are linked with birth defect registries, completeness of ascertainment and quality of diagnosis are assumed to be high. For some national registries, follow-up is virtually lifelong. These studies are also much more efficient than prospective registries: such studies can include a larger number of patients in a shorter time, and results can be available more quickly. In addition, prospectively collected data reduce the likelihood of recall bias, as exposure data can be collected prior to knowledge of the outcome. Finally, unlike prospective registries that terminate after reaching a target study size aimed at evaluating total birth defects, databases can be used to study larger numbers and potentially address questions about specific birth defects.

Notwithstanding, limitations associated with existing healthcare data should also be considered. These studies, like prospective registries, are limited by the size of the study population. In the case of MS, given that numerous treatments are available and that many women discontinue treatment when planning pregnancy, large or multiple databases need to be employed to observe a sufficient number of treated patients and comparators to allow for meaningful comparisons. In addition, healthcare databases collect data for routine purposes rather than for research. While this means all relevant patients will be included, some sources may not have access to all information necessary for ascertaining the exposure, outcome, or potential confounders. For example, the timing of exposure in relation to pregnancy can be difficult to determine from medication data provided. In these databases, a medication prescription or dispensing is assumed to mean exposure; if there are repeat prescriptions or dispensings, one can be more confident the patient actually took the medication. If the data source relies only on hospital discharge data, important outcomes that do not generally require hospitalization, including spontaneous abortions, terminations, and stillbirths, and covariates such as lifestyle factors, may not be captured. Furthermore, some data sources may restrict access to information on spontaneous abortions and terminations, due to the highly confidential nature of the events. Unless a nationwide or regional birth defect registry can be linked to the data or outcome validation can be implemented, confirming and appropriately categorizing major congenital malformations, and identifying minor malformations, can be difficult.

\section{Conclusion}

Studies of the potential impact of therapeutics on pregnancy and offspring outcomes face many methodological challenges. A variety of outcomes, which vary in frequency and best methods for identification, are of interest. To evaluate the safety of medications during pregnancy for women with MS, the current FDA approach is to request a treatment-specific or multidrug prospective pregnancy registry, singly, or in addition to another study with a different design. However, treatment-specific registries and other targeted studies have mostly failed to deliver timely and robust information. The limited amount of evidence accrued limits the conclusions that can be drawn. Until more robust studies can be conducted, recommendations are that women on DMTs take preventative measures to avoid pregnancy [30]. Studies in other disease areas have effectively used existing healthcare databases to evaluate safety of medications during pregnancy. While there is no perfect study design to overcome all limitations, to obtain more meaningful data for patients and physicians, regulatory agencies should consider alternative approaches to prospective treatment-specific registries to evaluate the safety of new medications among women with MS with exposure to DMTs during pregnancy. Viable approaches worthy of consideration include disease-specific prospective registries that collect data for all MS drugs and allow for the evaluation of specific drugs, studies using large population-based or healthcare claims data with linkage between mother and offspring, and multidatabase or multinational studies in which database-specific results are combined using appropriate methods to increase precision for study drugs with infrequent use and/or outcomes. While 
we chose MS as a case study, this conclusion may also apply to other disease areas.

Acknowledgements We would like to thank Adele Monroe at RTI Health Solutions for her editorial help.

\section{Compliance with Ethical Standards}

Funding This study was funded by F. Hoffmann-La Roche Ltd. DW, $\mathrm{BM}$, and $\mathrm{CH}$ were employees of F. Hoffmann-La Roche Ltd. at the time this research was conducted. EA, MA, WK, AM, ER, and CS are employees of RTI Health Solutions, an independent, non-profit research organization that does work for government agencies and pharmaceutical companies. Contract funding was paid by F. Hoffmann-La Roche Ltd. to RTI-HS (author's employer), not specifically to an individual, with retention of independent publication rights.

Open Access This article is distributed under the terms of the Creative Commons Attribution-NonCommercial 4.0 International License (http://creativecommons.org/licenses/by-nc/4.0/), which permits any noncommercial use, distribution, and reproduction in any medium, provided you give appropriate credit to the original author(s) and the source, provide a link to the Creative Commons license, and indicate if changes were made.

\section{References}

1. Saint-Raymond A, de Vries CS. Medicine safety in pregnancy and ambitions for the EU medicine regulatory framework. Clin Pharmacol Ther. 2016;100(1):21-3. doi:10.1002/cpt.378.

2. Gelperin K, Hammad H, Leishear K, Bird ST, Taylor L, Hampp $\mathrm{C}$, et al. A systematic review of pregnancy exposure registries: examination of protocol-specified pregnancy outcomes, target sample size, and comparator selection. Pharmacoepidemiol Drug Saf. 2016;. doi:10.1002/pds.4150.

3. INC Research. International Lemtrada pregnancy exposure cohort in multiple sclerosis: European Network of Centres for Pharmacoepidemiology and Pharmacovigilance. Document No.: OBS13436; 2014. http://www.encepp.eu/encepp/viewResource. htm?id=7575. Accessed 8 Dec 2015 .

4. Biogen. Tecfidera (dimethyl fumarate) pregnancy exposure registry: European Network of Centres for Pharmacoepidemiology and Pharmacovigilance. Document No.: TECGISTRY; 2015. http://www.encepp.eu/encepp/viewResource.htm?id=8379. Accessed 8 Dec 2015.

5. Li J, Fox RJ, Phillips JT, Havrdova E, Bar-Or A, Kappos L, et al., editors. Delayed-release dimethyl fumarate and pregnancy: preclinical studies and pregnancy outcomes from clinical trials and postmarketing experience. In: 31st Congress on the European Committee for Treatment and Research in Multiple Sclerosis, Barcelona; 2015.

6. Biogen. Biogen multiple sclerosis pregnancy exposure registry. ClinicalTrials.gov: US National Institutes of Health. Document No.: NCT01911767; 2015. https://clinicaltrials.gov/ct2/show/ NCT01911767. Accessed 8 Dec 2015.

7. Biogen. Fampridine pregnancy exposure registry. ClinicalTrials.gov: US National Institutes of Health. Report No.: NCT01532154 Document No.: NCT01532154; 2015. https:// clinicaltrials.gov/ct2/show/NCT01532154. Accessed 8 Dec 2015.

8. Geissbühler Y, Hortonada EP, Hashmonay R, Randhawa S, editors. Study design of a multinational Gilenya (fingolimod) pregnancy exposure registry. In: The 27 th annual meeting of the
CMSC and the 5th cooperative meeting of the CMSC-ACTRIMS, Orlando; 2013.

9. Geissbühler Y, Koren G, Wang H, Butzkueven H, Tilson H, Macdonald TM, et al., editors. Pregnancy outcomes after exposure to fingolimod and in the general population. In: 31st Congress on the European Committee for Treatment and Research in Multiple Sclerosis, Barcelona; 2015.

10. Novartis. The Multi-National Pregnancy Fingolimod Exposure Registry in Multiple Sclerosis. ClinicalTrials.gov: US National Institutes of Health. Document No.: NCT01285479; 2015. https:// clinicaltrials.gov/ct2/show/NCT01285479. Accessed 8 Dec 2015.

11. Biogen. Pregnancy exposure registry for Avonex (interferon beta1a). ClinicalTrials.gov: US National Institutes of Health. Document No.: NCT00168714; 2014. https://clinicaltrials.gov/ct2/ show/NCT00168714. Accessed 8 Dec 2015.

12. Foulds P, Richman S, Glick G, Onigman T, Hyde R. Pregnancy outcomes from the Avonex (interferon beta-1a) Pregnancy Exposure Registry. Mult Scler. 2010;16:S197-352.

13. Richman S, Wallace K, Liu S, Sperling B. Final results from the Avonex (intramuscular interferon beta-1a) pregnancy exposure registry. Neurology. 2012;78(suppl 1):P06.191.

14. Tomczyk S, Richman S, Wallace K, Liu S, Sperling B, editors. Final results from the Avonex (intramuscular interferon-beta-1a) pregnancy exposure registry. In: 28th Congress of the European Committee for Treatment and Research in Multiple Sclerosis, Lyon; 2012.

15. EMD Serono. Rebif pregnancy registry. ClinicalTrials.gov: US National Institutes of Health. Document No.: NCT00338741; 2013. https://clinicaltrials.gov/ct2/show/NCT00338741. Accessed 8 Dec 2015.

16. INC Research. Betaseron pregnancy registry. ClinicalTrials.gov: US National Institutes of Health. Document No.: NCT00317564; 2013. https://clinicaltrials.gov/ct2/show/NCT00317564. Accessed 8 Dec 2015.

17. Coyle PK, Sinclair SM, Scheuerle AE, Thorp JM Jr, Albano JD, Rametta MJ. Final results from the Betaseron (interferon beta-1b) pregnancy registry: a prospective observational study of birth defects and pregnancy-related adverse events. BMJ Open. 2014;4(5):e004536. doi:10.1136/bmjopen-2013-004536.

18. Biogen. Pregnancy exposure registry for Tysabri. ClinicalTrials.gov: US National Institutes of Health. Document No.: NCT00472992; 2014. https://clinicaltrials.gov/ct2/show/ NCT00472992. Accessed 8 Dec 2015.

19. Cristiano L, Friend S, Bozic C, Bloomgren G. Evaluation of pregnancy outcomes from the Tysabri (natalizumab) pregnancy exposure registry. Neurology. 2013;80(meeting abstracts):P02.127.

20. INC Research. An international pregnancy exposure registry of women with multiple sclerosis (MS) exposed to teriflunomide: European Network of Centres for Pharmacoepidemiology and Pharmacovigilance. Document No.: OBS12751. http://www. encepp.eu/encepp/viewResource.htm?id=8769; 2014. Accessed 8 Dec 2015.

21. Ebrahimi N, Herbstritt S, Gold R, Amezcua L, Koren G, Hellwig $\mathrm{K}$. Pregnancy and fetal outcomes following natalizumab exposure in pregnancy. A prospective, controlled observational study. Mult Scler. 2015;21(2):198-205. doi:10.1177/1352458514546790.

22. Hellwig K, Haghikia A, Gold R. Parenthood and immunomodulation in patients with multiple sclerosis. J Neurol. 2010;257(4):580-3. doi:10.1007/s00415-009-5376-z.

23. Lu E, Dahlgren L, Sadovnick A, Sayao A, Synnes A, Tremlett H. Perinatal outcomes in women with multiple sclerosis exposed to disease-modifying drugs. Mult Scler. 2012;18(4):460-7. doi:10. $1177 / 1352458511422244$.

24. Charlton R, de Vries C. Systematic overview of data sources for drug safety in pregnancy research: consultancy EMA/2010/29/ 
CN; 2012. http://www.encepp.eu/structure/documents/Data sources_for_medicines_in_pregnancy_research.pdf. Accessed 30 June 2016.

25. FDA. Study approaches and methods to evaluate the safety of drugs and biological products during pregnancy in the post-approval setting; public meeting, request for comments; 2014. http://www.fda.gov/Drugs/NewsEvents/ucm386560.htm. Accessed 2 Sept 2016.

26. FDA. Postmarket requirements and commitments: Zinbryta; 2016. http://www.accessdata.fda.gov/scripts/cder/pmc/index.cfm. Accessed 8 Sept 2016.

27. Hviid A, Melbye M, Pasternak B. Use of selective serotonin reuptake inhibitors during pregnancy and risk of autism. N Engl J Med. 2013;369(25):2406-15. doi:10.1056/NEJMoa1301449.

28. Mines D, Tennis P, Curkendall SM, Li DK, Peterson C, Andrews $\mathrm{EB}$, et al. Topiramate use in pregnancy and the birth prevalence of oral clefts. Pharmacoepidemiol Drug Saf. 2014;23(10):1017-25. doi:10.1002/pds.3612.

29. Molgaard-Nielsen D, Svanstrom H, Melbye M, Hviid A, Pasternak B. Association between use of oral fluconazole during pregnancy and risk of spontaneous abortion and stillbirth. JAMA. 2016;315(1):58-67. doi:10.1001/jama.2015.17844.

30. Alroughani R, Altintas A, Al Jumah M, Sahraian M, Alsharoqi I, AlTahan A, et al. Pregnancy and the use of disease-modifying therapies in patients with multiple sclerosis: benefits versus risks. Mult Scler Int. 2016;2016:1034912. doi:10.1155/2016/1034912.

31. Rog D, Seferta N, Daniel D, Mihalova T, Robinson M, Colilla S, et al., editors. LEMTRADA ${ }^{\circledR}$ (Alemtuzumab) Pregnancy Exposure Registry: study design and enrolment procedures for pregnant women with multiple sclerosis exposed to alemtuzumab. In: MS Trust 2015 Conference, Windsor; 2015. 